\title{
Health care planning teams and joint care planning teams: incompatible or complementary?
}

\author{
W E KEARNS, K MURRAY-SYKES, P MULLEN
}

One of the anomalies after the 1974 reorganisation of the National Health Service was the creation of joint care planning teams at area level and health care planning teams at district level, with no formal mechanism for direct communication between the two. The first mention of joint care planning teams was in a Department of Health and Social Security circular published in $1976 .{ }^{1}$ These teams were necessary to ensure joint planning between corresponding health authority and local authority. Their function was "to advise the NHS and local authorities on the development of strategic plans and guidelines covering priority services ... requiring a joint approach to planning." ${ }_{2}$ Their members were to be drawn from both authorities. The reason for creating areas in the 1974 reorganisation was to facilitate collaboration between health and local authorities, and so area was the appropriate level for such joint planning teams to be set up. The pattern in most areas was for the joint care planning team to be set up and for that team in turn to set up joint care planning team subgroups to consider particular groups such as the elderly and the handicapped. The subgroups reported to the joint care planning team, which reported to the joint consultative committee, which in turn advised the area health authority and local authority as appropriate.

At a slightly earlier stage, working to a DHSS circular published in $1973,{ }^{3}$ the district management team in most health districts set up health care planning teams to consider particular client groups or services. These teams reported to the district management team, which then drew up its plans and advised the area health authority accordingly. Their function was "to develop operational plans within the general framework of area health authority strategic and operational guidelines and to influence future strategies through commentary on these guidelines." ${ }^{2}$ Their membership was to be broadly representative and to include local authority officers. How the two sets of teams were to avoid duplication of effort or coming up with conflicting advice was never made clear. Arrangements were particularly confused because in most cases health care planning teams had been set up from 1974 onwards, whereas the first mention of joint care planning teams and their subgroups came in 1976. District based planning was therefore well established before area based joint care planning teams were considered. The potential for confusion and acrimony was enormous, and unfortunately this potential was realised in many areas.

The newly formed district health authorities are now setting up planning teams. The 1982 DHSS circular on the NHS planning system ${ }^{4}$ lays the basis for the reintroduction of the previous confusion. The circular suggests that it may be "advisable for neighbouring district health authorities to

\footnotetext{
Department of Community Medicine, Paddington and North Kensington Health Authority, St Mary's Hospital, London W2 1NY W E KEARNS, MB, FFCM, district medical officer

K MURRAY-SYKES, BA, director of community medicine and nursing research unit

Health Services Management Centre, University of Birmingham P MULLEN, MSc, lecturer

Correspondence to: Dr W E Kearns.
}

co-ordinate their planning." It also states that "arrangements for joint planning will continue on the same lines as at present subject to any modifications required by restructuring." The information that follows may be helpful to district health authorities in their deliberations. The information was obtained during visits by $\mathrm{KM}-\mathrm{S}$ to 50 . districts and areas in England in 1980 as part of a national survey of planning teams. ${ }^{5}$ The experiences of single district areas may be of particular relevance to the current position. Some of the problems found in multidistrict areas are unlikely to be relevant to the newly restructured NHS, but there are possible implications where services must be run, planned, or co-ordinated on a multidistrict basis.

\section{Findings}

THE RELATION IN PRACTICE-MULTIDISTRICT AREAS

Given that all districts and areas were working in the same basic structure after the 1974 reorganisation, it is interesting that such different patterns of relations emerged. This is one of the problems of trying to design one structure that is expected to work well in a variety of settings. The patterns that were observed in the multidistrict areas visited during this research may be defined in four ways: good, poor, indifferent, and different.

Good relations occurred where the area and the districts saw their planning roles as complementary. For example, in one area the joint care planning team dealt mainly with joint financing schemes. The joint care planning team included in its membership the district community physicians from each of the three districts in the area, and this provided a channel for the communication of joint financing proposals from district health care planning teams. In return, the district health care planning teams all included members of the area capital services and information group, which ensured that the district teams received all relevant up to date information from the area. In another area the joint care planning team dealt with joint financing but had also set up subgroups which had prepared strategies for the elderly, handicapped, mentally handicapped, and mentally ill. The district health care planning teams fed into these area groups to influence and be influenced by them. Elsewhere joint care planning team subgroups covered services which were more sensibly planned on an area rather than district basis.

Poor relations were characterised by duplication of effort and a lack of communication, as the following quotations indicate: "Mental handicap services are planned by teams at both district and area level, with very little common membership and no exchange of information" (a district community physician). "The joint care planning team has subgroups which produce lots of reports but have no final impact on anything" (a planning administrator). Several districts were scathing about their relation with their area, and the general feeling was that the planning teams at area were ineffective and wasteful. According to one district community physician: "Internal communication is not good. As a result, proposals which do not filter down are not implemented." The fact that joint care planning teams had access to joint finance and were under no obligation to consult the districts about how such money was spent meant that in some districts the effects of poor communication were more serious. In one district a joint assessment unit was being built for medical and social services to assess elderly people. The health care planning team for the elderly in the district in question was not consulted until the building was under construction, at which stage they were asked what staff the district could provide.

Indifferent relations were those where the districts usually had some form of representation on the joint care planning team and its subgroups or both, and these teams were viewed as fairly harmless. 
They were not a source of conflict and in the words of one district community physician: "the subgroups do not detract from the (district) planning teams. Actual proposals for improvements in health care must come through the district management team." In another district the joint care planning team subgroups at area were seen as a useful way of deflecting pressure from the local authority away from the district health care planning teams. In this case the district had refused to allow the local authority to take over its planning teams, so the local authority had concentrated on the area teams.

Different relations were found in several multidistrict areas which were experimenting with methods of planning outside the basic structure. In one area it had been decided that joint planning should become a district function, as each district in the area was conterminous with a local authority. The area's role in joint planning was therefore redundant. Another district had to deal with three local authorities and had therefore set up three joint consultative committees at district level. The district planning teams were able to relate directly to the district joint consultative committees, which were then able to develop policies with the local authorities and influence objectives and provision. In another area the area and the districts combined their planning efforts. Special planning groups had been set up which reported to the joint care planning teams. Each district had representatives on these groups and servicing was shared between the districts and the area. One London area had adopted more revolutionary methods and had stopped planning according to district boundaries. The joint care planning team had set up three subgroups for each client group-that is, three teams planning services for the elderly, three for mental handicap, etc-to match the borough boundaries. Each district had representation on the relevant teams.

\section{EXPERIENCE IN SINGLE DISTRICT AREAS}

DHSS guidance on setting up health care planning teams ${ }^{6}$ followed by guidance on setting up district planning teams and joint care planning teams ${ }^{2}$ posed particular problems for single district areas. Interpretation of the guidelines varied in and between areas, with the result that some single district areas decided to concentrate on health care planning teams, others concentrated on joint care planning teams, and a third group set up two sets of teams.

Concentration on health care planning teams seems to have occurred mainly by default rather than by design. Several single district areas had set up many health care planning teams shortly after the 1974 reorganisation and were only beginning to think seriously about placing more emphasis on joint planning with the local authority some five or six years later. Another single district area had no joint care planning team and its joint consultative committee met for only a nominal half hour once a year. The health care planning teams all included local authority representatives and were considered to fulfil the function of a joint care planning team. The joint consultative committee in one single district area was still discussing the possibility of setting up a joint care planning team, but the local authority was said to be uncooperative. In this case it was thought that if the area did ever manage to set up a joint care planning team then the health care planning teams would go into recess.

Concentration on joint care planning teams in some single district areas was the result of never having set up health care planning teams in the first place. These areas reacted to the later guidelines issued by the DHSS ${ }^{2}$ and set up joint planning teams to deal with matters of great concern to both social services and the area health authority. Other single district areas had set up health care planning teams first and had then disbanded these in favour of joint care planning teams when the 1977 DHSS circular came out. ${ }^{2}$ In one single district area the only difference between the health care planning teams and the joint planning groups was the increase in local authority representation. Although in theory these joint planning groups reported to the joint care planning team, which reported to the joint consultative committee, which then advised the area health authority and local authority departments, in practice no proposals went to the joint consultative committee unless they had been discussed by the area management team first. This was achieved by the area management team having two representatives on the joint care planning team. This area had retained its maternity health care planning team as it was not thought necessary to make this a joint planning group.

In contrast, the effect of the 1977 DHSS circular in another single district area had been much more traumatic. There was disagreement in the area about whether joint planning with the local authority was an additional activity to that of health care planning teams and so required one team to cover both functions or whether it was a separate activity requiring two sets of teams. In the event, some professional groups withdrew their representatives from health care planning teams because they did not have enough staff to support both health care planning teams and joint care planning teams. Health care planning teams were therefore abandoned and the decision made to do all planning through the joint care planning team. This single district area and the majority of other single district areas, which had decided to concentrate on joint care planning teams rather than health care planning teams, expressed concern about the drawbacks of this method of planning. This will be discussed later.

Both health care planning teams and joint care planning teams existed in a few single district areas. In one place the main comment about this was that the joint care planning team got better, higher level representation from the local authority than the health care planning teams. In another single district area the joint care planning team did not relate to any of the planning teams or to the joint consultative committee: "No one knows what the joint care planning team or joint consultative committee do. The joint care planning team has set up its own subgroups which do not relate to area planning teams. There is no feedback from joint care planning team subgroups." This lack of communication was relatively common between areas and their districts, but unusual within a single district area.

\section{Main problem areas}

Some form of joint planning between health and local authorities is needed. ${ }^{4}$ Although it is possible that some district health authorities may have to set up health care planning teams rather than joint care planning teams, this is unlikely to be a preferred alternative. The problems in areas where there is little cooperation between the two authorities will not be discussed here. The main purpose of this section is to examine the potential problems of the joint care planning team system and of a combined health care planning team and joint care planning team system, so that district health authorities may modify their joint planning arrangements according to local circumstances.

\section{JOINT CARE PLANNING TEAM SYSTEM}

\section{Shift in priorities}

By their very nature joint care planning teams will concentrate on issues of concern to the health authority and the local authority. This has been reflected in the joint care planning team subgroups that have been set up and in the issues discussed by those subgroups. A common complaint made by health authority officers has been that health issues have not been dealt with adequately. If there are major local health issues which require discussion by a multidisciplinary team it is important that appropriate mechanisms exist for these discussions to take place.

\section{Confusion of role}

A quotation from a community physician in a single district area best illustrates this problem: "Minutes of the joint care planning team subgroups go to the joint care planning team. Anything relevant to both authorities is referred to the joint care planning team, but things which are only relevant to one authority go to that authority direct. The dual role of providing operational health planning support and getting involved in joint planning with the local authority has meant that the health side has never been dealt with adequately. But yet joint planning has not really worked either. There is no real attempt to get together constructively and work out joint strategies. Teams are just seen as a forum for spending joint financing money and people come along with their own pet schemes." There is an obvious danger that teams will be expected to fulfil too many functions and end up being inadequate in all respects.

\section{Concentration on joint finance}

It is a widely held belief that joint care planning teams tend to concentrate on how to spend joint finance and that they make no 


\section{Model for joint planning (1)}

Where the district health authority and local authority are conterminous and where there is a good relation between the officers in the two authorities and a genuine commitment to joint planning, authorities should give careful consideration to a combination of:

A single joint care planning team-with membership fully representative of each authority and a remit to coordinate strategy and recommend the disposition of joint financing money.

Joint care planning team subgroups-each set up by the joint care planning team with a multiauthority membership to provide operational and strategic planning advice on a particular care group to the joint care planning team. These subgroups could set up ad hoc working parties to consider particular issues in greater depth.

District planning teams-set up by the district health authority to consider client groups or services not covered by the joint care planning team subgroups because they are of more relevance to the health authority than to the local authority. These teams would report directly to the district management team.

Local authority planning teams-the local authority equivalent of district planning teams.

There should be no conflict or overlap between the recommendations of the above teams. The operational plan produced by the district health authority would combine appropriate recommendations from the joint care planning team subgroups and district planning teams within the overall strategy agreed by the joint care planning team. Coordination would be facilitated if the district planning officer and a community physician or both were members of every team.

serious attempt to plan jointly in any systematic or comprehensive fashion. Given that joint finance is also often spent on convenient schemes (those without revenue consequences or which fit in with a current enthusiasm) rather than schemes taken from a carefully planned framework of priorities, planning is not a word that should really be applied to this activity.

\section{Introduction of party politics}

A quotation from another single district area illustrates what to some people is a suspicion but to others is already a reality: "Not all aspects of health care can be dealt with through the joint care planning team. Some things are not relevant to the local authority. But having to do everything through the joint care planning team makes health recommendations dependent on approval from local authority officers. The local authority is inclined to do whatever is most politically acceptable. Health care planning should not be subservient to that."

\section{Tendency to become a peripheral activity}

In some single district areas operating a joint care planning team system, what was considered to be "real" planning had become an entirely separate management exercise. According to one administrator, joint care planning team subgroups were'" all peripheral to the overall planning system in the area." In another area the teams did not see the operational plan until the consultation stage. This particular area health authority had financial problems and thought that "discussions on reallocation and retrenchment are not suited to a joint committee with the local authority." In the current financial climate this latter point is likely to be of concern to many district health authorities. Joint care planning has always been peripheral to local authority planning in this respect.

COMBINED HEALTH CARE PLANNING TEAM AND JOINT CARE PLANNING TEAM SYSTEM

If two separate sets of teams are set up, one set to fulfil the roles $\mathbb{D}$ of district health care planning teams and the other set to fulfil the roles of joint care planning team subgroups, then the following problems are likely: some role confusion and duplication of effort; strain on staffing resources because of the number of meetings; tendency for some professional groups to give higher priority to one set of teams than the other, leading to a diminished input from representatives on some teams; communication problems; provision of conflicting advice; and complicated reporting arrangements leading to delays in implementation of plans.

\section{Discussion}

Since 1974 most health districts have come to recognise the need for district health care planning teams. The multi- iv disciplinary membership of these teams provides a forum unique $\stackrel{\circ}{\circ}$ in the NHS for discussing health care issues and the provision of planning advice to the district management team. The full $\stackrel{\infty}{\rightarrow}$ potential for health care planning teams has not been tapped in many districts, but it would be a retrograde step to disband them in favour of a system that may prove to be less effective.

The need for joint planning with the local authority is also 을 recognised by most health authorities. It is particularly $\overrightarrow{ }$ important in a time of rationalisation rather than expansion in $\bar{c}$ both health and social services that strategies should be jointly planned. It is also important for the two authorities to consider carefully how joint financing money may best be utilised locally. Some sort of joint care planning team is therefore essential.

The extent to which the activities of joint care planning teams and district health care planning teams were likely to overlap may be seen clearly in the 1977 DHSS circular. ${ }^{2}$ This states: "There should be a continuing exchange of views about the future pattern and development of services between planners at district and area ... to ensure that each is aware of, and responds at an early stage to, ideas put forward by the others." Unfortunately, how this continuing exchange was to be achieved was not specified. It is a sad reflection on the state of collaboration between health districts and areas, let alone between health authorities and local authorities, that planning arrangements were so unsatisfactory in so many places.

The fact that the 1982 restructuring of the NHS has created some district health authorities that are not conterminous with a local authority is an added complication. The setting up of several sets of planning teams to deal with several different local authorities would be wasteful in terms of NHS staff 윽 resources but may be unavoidable, particularly if relations $N$ between the various local authorities are strained. The same $\rightarrow$ would apply to the participation of local authority staff in health care planning teams in two or more health districts. $\vec{N}$ Joint planning teams between two or more district health $\mathrm{N}$ authorities relating to the same local authority or local authorities are a possibility; such teams would be justified only if there was a real requirement for joint planning and would therefore $\stackrel{\circ}{C}$ report to the joint care planning team. Any need to report also 市 to district management team and district health authority would introduce a further complication.

Whatever planning systems are adopted by the new district health authorities, it is unlikely that one system will suit all districts. Given the many constraints on joint planning and the problems encountered by so many health authorities since 1974, a flexible approach is obviously crucial.

The first step in determining local planning arrangements must be a consideration of local factors that may influence their success. Some of the issues are uncomfortable to think about 
but must be faced so that difficulties may be anticipated. If any problems are considered insurmountable these problems should be taken into account in the local planning structure.

\section{CHECKLIST}

Do health authority and local authority genuinely intend to cooperate at all ?

Do health authority and local authority want to plan jointly from an early stage or would they prefer to plan independently then discuss each other's plans at a later stage?

Is there really an opportunity to put proposals that have been jointly discussed into the local authority machinery?

Will there be any commitment on the part of the local authority to follow planning advice put forward by the joint care planning team ?

Will joint planning between the health and local authority be solely concerned with the spending of joint finance?

How can joint finance be spent within a carefully planned framework of priorities?

How can issues of particular concern to the health authority or to the local authority, but not of equal concern to both, be adequately covered within a joint planning framework ?

Should health care planning teams restrict their discussions to issues where implementation of proposals is solely the responsibility of the health authority, leaving joint planning entirely to the joint care planning team?

Should any issues be planned solely by the NHS ? Even acute services have implications for local authorities-for example, if a shorter length of stay or an increase in surgical day cases is planned there will be an impact on social services.

Are discussions on retrenchment and reallocation really not suitable for joint discussion or are people in both authorities apprehensive about exposing to close scrutiny the reasoning behind particular decisions?

How will health care planning teams relate to the joint care planning team-for example, will health care planning team chairmen be members of the joint care planning team ?

\section{Model for joint planning (2)}

Where the district health authority has to relate to more than one local authority or where relations between the various authorities are fairly restrained it might be more appropriate to have:

District planning teams-set up by the district health authority including local authority representation, to cover client groups and services of concern to the district health authority. These teams would report directly to the district management team.

Local authority planning teams-set up by the local authority, including health authority representation, to cover client groups and services of concern to the local authority.

One joint care planning team for each local authoritywith membership divided equally between the district health authority and the local authority, including the chairmen of each of the district and local authority planning teams. This team would determine strategy and the disposition of joint financing money. Its membership should ensure adequate coordination and communication because all the planning teams and both authorities would be represented.
At what stage should the district management team and district health authority be advised of proposals by health care planning teams-before or after the joint care planning team-or will the joint care planning team include the district management team in its membership?

Will the joint care planning team consider some service groupsfor example, those of equal concern to both the health authority and the local authority-and health care planning teams consider othersfor example, those of concern to both authorities but of most concern to the health authority?

If the district health authority and local authority boundaries do not match what are the options for joint planning ? How will one district health authority relate to several local authorities and vice versa, where boundaries are not one to one?

What are the other local circumstances that make planning for some individual service groups particularly difficult? One is personality problems-for example, basic disagreements between consultants and staff from other disciplines can make the implementation of some proposals impossible-and another conflicting prioritiesfor example, the facts may point to one course of action, but this may be politically unacceptable to local pressure groups, the local authority, members of the health authority, trade unions, etc.

Do senior managers or authority members really want a genuinely participative planning system, or are planning teams intended to perform a rubber stamping or liaison function? Intentions should be made clear so that highly paid professional time is not wasted trying to fulfil a function that was never intended in the first place.

What level of representation is required from each professional group concerned in planning teams? If the objectives of the teams are clarified the type of representation required can be identified.

What will be the precise lines of communication between all people and bodies concerned in planning?

Who will arbitrate when conflicting advice or proposals are put forward?

\section{Conclusion}

The introduction of a comprehensive multidisciplinary approach to health care planning was one of the major aspirations of the 1974 reorganisation of the NHS. Between 1974 and 1981 many health care and joint care planning teams were set up. The amount of professional time spent on planning activities is enormous and it is essential that this time is well spent. Doctors constitute $40 \%$ of the membership of health care planning teams and chair nearly $90 \%$ of them. The current restructuring of the NHS offers a good opportunity for improving local planning arrangements. Planning expectations must be adjusted to take account of local factors, and clear and realistic guidance for all planning teams is essential if their maximum potential is to be realised.

We are grateful for the financial help given by the King's Fund to carry out this research, and for the time and thoughts so willingly shared by the many community physicians and administrators interviewed during the study.

\section{References}

1 Department of Health and Social Security. Foint care planning: health and local authorities. HC(76)18. London: DHSS, 1976.

2 Department of Health and Social Security. Foint care planning: health and local authorities. HC(77)17. London: DHSS, 1977.

${ }^{3}$ Department of Health and Social Security. Management arrangements for the reorganised NHS. HRC(73)3. London: DHSS, 1973.

${ }^{4}$ Department of Health and Social Security. Health services developmentthe NHS planning system. HC(82)6. London: DHSS, 1982.

${ }^{5}$ Mullen PM, Murray-Sykes K, Kearns WE. Survey of planning teams: methodology and basic results. Occasional paper No 29. Birmingham: University of Birmingham Health Services Management Centre, 1981.

${ }^{6}$ Department of Health and Social Security. Health care planning teams. London: DHSS, 1975. 